\title{
Role of Inflammasomes in Neuroimmune and Neurodegenerative Diseases: A Systematic Review
}

\author{
Yue Lang $\mathbb{D}^{1},{ }^{1}$ Fengna Chu ${ }^{D},{ }^{1}$ Donghui Shen ${ }^{(D},{ }^{1}$ Weiguanliu Zhang, ${ }^{1}$ Chao Zheng, \\ Jie Zhu $\mathbb{D}^{1,2}$ and Li Cui ${ }^{1}{ }^{1}$ \\ ${ }^{1}$ Department of Neurology and Neuroscience Center, First Hospital of Jilin University, Changchun, Jilin Province, China \\ ${ }^{2}$ Department of Neurobiology, Care Sciences \& Society, Division of Neurodegerneration, Karolinska Institutet, Karolinska University \\ Hospital Huddinge, Stockholm, Sweden
}

Correspondence should be addressed to Jie Zhu; jie.zhu@ki.se and Li Cui; chuili1967@126.com

Received 26 October 2017; Revised 26 December 2017; Accepted 1 January 2018; Published 17 April 2018

Academic Editor: Donald Staines

Copyright ( 2018 Yue Lang et al. This is an open access article distributed under the Creative Commons Attribution License, which permits unrestricted use, distribution, and reproduction in any medium, provided the original work is properly cited.

\begin{abstract}
Inflammasomes are multiprotein complexes that can sense pathogen-associated molecular patterns and damage-associated molecular signals. They are involved in the initiation and development of inflammation via activation of IL-1 $\beta$ and IL-18. Many recent studies suggest a strong correlation between inflammasomes and neurological diseases, such as multiple sclerosis (MS), Alzheimer's disease (AD), and Parkinson's disease (PD). Several components of inflammasomes, such as nucleotide-binding oligomerization domain- (NOD-) like receptor, absent in melanoma 2- (AIM2-) like receptors (ALRs), apoptosis-associated speck-like protein containing a caspase recruitment domain (ASC), and caspase-1, as well as the upstream factors and downstream effectors, are associated with the initiation and development of MS and its animal model, experimental autoimmune encephalomyelitis. Additionally, inflammasomes affect the efficacy of interferon- $\beta$ therapy in patients with MS. Finally, the strong association of inflammasomes with $\mathrm{AD}$ and $\mathrm{PD}$ needs to be further studied. In this review of latest literatures, we comprehensively tease out diverse roles of different kinds of inflammasomes in neuroimmune and neurodegenerative diseases, especially in the perspective of double roles involved in pathogenesis, and identify future research priorities.
\end{abstract}

\section{Introduction}

Inflammasomes are multiprotein complexes with an inherent ability to elicit innate immune responses by sensing damage signals and microbial attack [1]. Inflammasomes exist in the cytosol of several types of cells, including immune cells (such as T cells, B cells, dendritic cells, and macrophages), neural cells [2], microglia [3], and astrocytes [4] as well as pulmonary endothelial cells [5]. Inflammasomes play a critical role in the development of neurological, immune, and neurodegenerative diseases, such as multiple sclerosis (MS), Alzheimer's disease (AD), and Parkinson's disease (PD). The multimeric complexes in inflammasomes have classically been referred to as "damage sensors," since nucleotidebinding oligomerization domain- (NOD-) and absent in melanoma 2- (AIM2-) like receptors recognize and interact with pathogen-associated molecular patterns, which in turn trigger a series of immune reactions. Recently, there has been an increase in the research on inflammasomes. Several studies have documented the increased inflammasome components and inducing factors, such as adenosine triphosphate (ATP) and uric acid, during the development of MS and experimental autoimmune encephalomyelitis (EAE), an animal model of MS. In this work, we provide a comprehensive overview of the role of inflammasomes in neuroimmune and neurodegenerative diseases based on a review of contemporary literature.

\section{Structure and Function of Inflammasomes}

Inflammasomes contain three components: sensors, apoptosis-associated speck-like protein containing a caspase recruitment domain (ASC), and an enzymatic component. Based on the structural features, sensors can be classified into three types: NOD-like receptors (NLRs), AIM2-like receptors (ALRs), and pyrin. The sensors have the ability 
to detect pathogen-associated molecular patterns (PAMPs) [6] or damage-associated molecular patterns (DAMPs) and cytosolic double-stranded DNA [7]. Detection of these stimuli triggers the assembly of the three components based on the nucleating ability of the pyrin domain (PYD) and the caspase recruitment domain (CARD) $[8,9]$. The assembled complexes act as proteolytic cleavers which activate the precursor of interleukin- $1 \beta$ (IL-1 $\beta$ ) and IL-18, which are involved in a series of immune and inflammatory processes [10-12]. The NLR family, pyrin domain-containing 1 [13], 3 [14], 4 [15], and 12 [16] (NLRP1, NLRP3, NLRP4, and NLRP12, resp.), are NLRs that have been shown to be involved in inflammasome assembly, while AIM2 is the most well-characterized ALR. AIM2 detects DNA through a HIN domain [17], while NLRP3 [18] detects intracellular DNA by the stimulator of IFN genes- (STING-) mediated DNAsensing pathway [18]. In general, IL- $1 \beta$ is cleaved by caspase- 1 . However, some previous studies also indicated that IL-1 $\beta$ can be processed by caspase- 8 [19] or caspase-11 through a noncanonical inflammasome [20].

Most inflammasomes promote inflammation by inducing production of inflammatory factors IL- $1 \beta$ and IL-18. However, some inflammasomes also have anti-inflammatory effects. The inhibitory effect of NLRX1 on microglialinduced inflammation in EAE was first reported by Eitas et al. [21]. Moreover, inflammasomes are capable of maintaining the balance of the gut microflora and prevent enteritis from progressing to a tumor [22].

\section{Factors Involved in Inflammasome Activation and Regulation}

Since inflammasomes lower the threshold of immune response [23], the search for the factors involved in their activation and regulation aiming at identifying therapeutic targets against autoimmune disease has evoked much interest. The initiation of inflammasomes is not well characterized; however, the following mechanism of activation of NLRP3 has been described: First, the bacterial or viral RNA [24], ATP [25], uric acid crystals [26], silica [27], and other similar factors interact with toll-like receptors (TLRs), NOD2, TNFR1, or TNFR2 to induce a cellular expression of NLRP3. Second, PAMP or DAMP triggers NLRP3 to initiate inflammasome formation. In the first stage, P2X7/ P2X4 has been shown to be a receptor of ATP [28], whereas pannexin 1 (Panx1) mediates the release of ATP from cells [29]. P2X(4) receptors are another important signal that activates inflammasomes. It has been reported that P2X(4) influences NLRP1 inflammasome signaling in spinal cord injury [30] and osteoarthritis [31]. Moreover, biglycan, a kind of leucine-rich repeat proteoglycan, can also activate NLRP3 inflammasomes through interaction with TLR2/4 and purine $\mathrm{P} 2 \mathrm{X} 4 / \mathrm{P} 2 \mathrm{X} 7$ receptors on macrophages [32]. Antiapoptotic proteins, activated $\mathrm{T}$ cells, and microRNAs are negative regulators of inflammasomes [33]. Tumor necrosis factor (TNF) $\alpha$-induced protein 3 (TNFAIP3) and the binding of antiapoptotic proteins $\mathrm{Bcl}-2$ and $\mathrm{Bcl}-\mathrm{X}(\mathrm{L})$ have been shown to dampen the NLRP1 inflammasome $[34,35]$. NF- $\kappa \mathrm{B}$ is also one of the activation signals for inflammasomes [36]. Atorvastatin was shown to suppress inflammasomes in monocytes via the TLR4/MyD88/NF- $\kappa$ B pathway [37]. The myeloid-specific microRNAs, miR-223 and miR-7, suppress NLRP3 inflammasome activity via inhibition of NLRP3 protein expression [38, 39]. Mouse effector and memory $\mathrm{CD} 4^{+} \mathrm{T}$ cells were shown to suppress inflammasomes of macrophages via cell-to-cell contact [40]. Human $\mathrm{CD} 4^{+}$memory $\mathrm{T}$ cells suppress NLRP3 activation by downregulating P2X7R signaling [41]. Furthermore, it has been reported that caspase-12 associated with caspase- 1 inhibits its activity [42]. In addition, polyoxotungstate-1 (POM-1) can inhibit the events related with ATP-dependent inflammasome activation [43]. Probenecid, a Panx1 inhibitor, protects against oxygen-glucose deprivation injury in primary astrocytes by regulating inflammasome activity [44]. Moreover, one interesting finding is that in primary macrophage cultures, low intracellular $\mathrm{K}(+)$ and the membrane channel Panxl induce inflammasome activation, while in the primary neuron and astrocyte cultures, high extracellular potassium opens Panx1 channels leading to caspase-1 and inflammasome activation [45]. The reason for this discrepancy is still unclear; it is surmised that there might be an unknown factor suppressing caspase-1. Factors that negatively regulate inflammasome activity are shown in Table 1.

\section{Inflammasomes in MS/EAE}

MS is an immune-mediated, chronic inflammatory demyelinating disease of the central nervous system (CNS). The hallmark of MS is recurrent neurological dysfunction and a progressive disease course. EAE is an animal model of MS [46] that is characterized by mononuclear cell infiltration around small vessels and demyelination in CNS mediated by specific sensitized $\mathrm{CD} 4^{+} \mathrm{T}$ cells.

Dumas et al. [47] demonstrated that the pertussis toxin could promote the formation of a pyrin-dependent inflammasome in EAE. Elevated levels of IL-1 $\beta$ have also been reported in the cerebrospinal fluid (CSF) of MS patients before clinical relapse, and caspase- 1 expression is detected in MS plaques [48].

EAE mice with NLRP3 gene knockout experienced a different disease course. The NLRP3 ${ }^{-/-}$mice had a significantly delayed disease course and less severe disease [49]. Subsequently, the higher dose of immunizing agents in $\mathrm{ASC}^{-1-}$ and $\mathrm{NLRP}^{---}$mice implies that inflammasomes are involved in the progression of EAE. Additionally, the amount of inflammasome-associated protein mRNA, such as in NLRP1, caspase-1, caspase-3, ASC, and pro-IL-1 $\beta$, were shown to be elevated 2 weeks after injection of myelin oligodendrocyte glycoprotein peptide [13, 50-53]. In a chlorpromazine- (CPZ-) induced demyelination mouse model, the progesterone treatment group exhibited a decrease in neurological behavioral deficit scores accompanied by decreased levels of NLRP3 inflammasomes [54]. This research suggests that NLRP3 inflammasomes are involved in the pathogenesis of the CPZ-induced demyelination mouse model. Moreover, the occurrence of MS-like symptoms in patients with other autoimmune diseases and inflammasome-associated genetic mutations indicates that 
TABLE 1: The negative regulation factors of inflammasomes.

\begin{tabular}{lcc}
\hline Regulation of factors & Target & Mechanism \\
\hline A20/TNFAIP3 [34] & NLRP1 & Binding with Bcl-2 and Bcl-X(L) \\
miR-223 [38] & NLRP3 & Acting on a conserved binding site within 3' untranslated region of NLRP3 \\
miR-7 [39] & NLRP3 & Posttranscriptionally controlled NLRP3 expression \\
Human CD4 ${ }^{+}$memory T cells [41] & NLRP3 & Down-regulation of P2X7R signaling molecules \\
Caspase-12 [42] & Caspase-1 & Associated with caspase-1 \\
POM-1 [43] & NLRP1 & Inhibit the events related with ATP-dependent inflammasome \\
Probenecid [44] & NLRP3 & Block pannexin 1 channel and high extracellular potassium \\
Type I interferons [86] & NLRP1/NLRP3 & Via the STAT1 transcription factor \\
\hline
\end{tabular}

A20/TNFAIP3: tumor necrosis factor $\alpha$-induced protein 3; NLRP1/NLRP3: NOD-like receptors pyrin domain-containing 1 or 3; POM-1: polyoxotungstate-1.

inflammasomes are involved in the pathogenesis of MS. For example, mutations of the pyrin domain of Mediterranean fever gene (MEFV gene) have been linked to a higher susceptibility to more progressive or severe MS [55-57]. Patients with familial Mediterranean fever who have CAPSassociated V198M and Q703K mutations tend to experience MS (with comorbidity reaching as high as 53\%) [58]. Magnetic resonance imaging of the brain of one patient with Muckle-Wells syndrome showed MS-like pathology [59, 60].

However, not all NLRP proteins promote inflammation. Anti-inflammatory actions of NLRX1 have been demonstrated in EAE, and $\mathrm{NLRX1}^{-1-}$ mice were shown to display higher clinical scores than wild-type controls were [21]. Additionally, NLRP12 also inhibits the nuclear factor- $\kappa \mathrm{B}$ (NF- $\kappa \mathrm{B}$ ) pathway by interacting with NF- $\kappa \mathrm{B}$-inducing kinase and the TNF receptor-associated factor (TRAF) 3 in innate immune cells without inflammasome formation [61-63]. Inflammatory response in the NLRP $12^{-/-}$mouse EAE model is much stronger than that in the control group [64].

\section{The Role of Inflammasomes in the Pathogenesis of MS/EAE}

Inflammasomes promote activation of both IL- $1 \beta$ and IL-18 and migration of Th1 and Th17 cells into CNS. Although there is no consensus as to whether pyrin promotes [65] or inhibits [66] the function of inflammasomes, the inflammasomes are believed to play a critical role in neuroimmune diseases.

IL- $1 \beta$ and IL-18 are the effectors of inflammasomes. IL- $1 \beta$ has been detected in white and gray matter lesions in a mouse EAE model [67]. In this model, IL- $1 \beta$ is secreted by infiltrating monocytes [68] and meningeal mast cells [69], while in a rhesus EAE model, IL-1 $\beta$ is mainly induced in the CNS itself [70]. Since IL-1 $\beta$ is associated with impairment of the blood-brain barrier and the blood-spinal cord barrier [71, 72], it is believed to promote immune cell migration into the CNS, which is a crucial link to EAE. Moreover, IL-1 $\beta$ is known to affect $\mathrm{T}$ cell responses [73]. It is secreted by mast cells and induces the expression of the granulocyte-macrophage colony-stimulating factor (GM-CSF), which is an important factor in T cell encephalitogenicity [74]. Besides, IL-1 $\beta$ induces the differentiation of Th17 cells [75] and subsequently aggravates EAE [76]. IL-18 was shown to promote autoimmunity by stimulating innate IL-17 production by T cells [77], and the increased levels of serum IL-18 in patients with MS illustrate its key role in the pathogenesis of MS [78].

Th1 and Th17 cells are critical to the progress of EAE [79], and the inflammasomes were shown to induce EAE via modulation of their autoimmune response. Gris et al. [49] demonstrated that NLRP3 could possibly impair Th1 and Th17 responses by affecting caspase-1-dependent cytokines, and hence, NLRP3 could induce EAE. However, there are conflicting views pertaining to the role of Th17 in the $\mathrm{NLRP3}^{-1-}$ and $\mathrm{ASC}^{-1-}$ mouse EAE models. Inoue et al. [80] reported that reduction in Th17 is not crucial for a reduced clinical score in the $\mathrm{NLRP}^{-/-}$and $\mathrm{ASC}^{-1-}$ mouse EAE models.

Moreover, inflammasomes could also enhance EAE by affecting Th1 and Th17 immigration to the CNS. Inoue et al. reported that NLRP3 inflammasomes do not induce an increase in the population of Th17 cells; instead, they contribute to $\mathrm{T}$ cell chemotactic activity in the CNS [80]. During the process, $\mathrm{CD}^{+}{ }^{+} \mathrm{T}$ cells are activated by IL- $1 \beta$ and IL-18 produced by antigen-presenting cells (dendritic cells and macrophages), which have copious amounts of inflammasomes; as a consequence, there is an increase in the expression levels of chemotaxis-related proteins (such as osteopontin, CCR2, and CXCR6) [80].

In addition, inflammasomes are the cofactor of some substances that are involved in EAE pathogenesis, such as integrin-associated protein (IAP) CD47 and Panx1. In vivo administration of exogenous IL- $1 \beta$ has been shown to promote the infiltration of $\mathrm{CD} 47^{--}$Th17 cells into the CNS. Mechanically, blocking of CD47 activates Src, subsequently inducing and then decreasing the degradation level of inducible nitric oxide synthase. As a result, the level of nitric oxide (NO) increases and suppresses inflammasome activation-induced IL- $1 \beta$ production. As mentioned previously, lower IL- $1 \beta$ reduces the expressions of IL-1R and migration-related chemokine receptors on Th17 cells, thereby suppressing EAE development [81]. The reason why the plasma membrane channel Panxl could contribute to EAE progression is that Panx1 mediates ATP release and further triggers inflammasome activation [82]. 


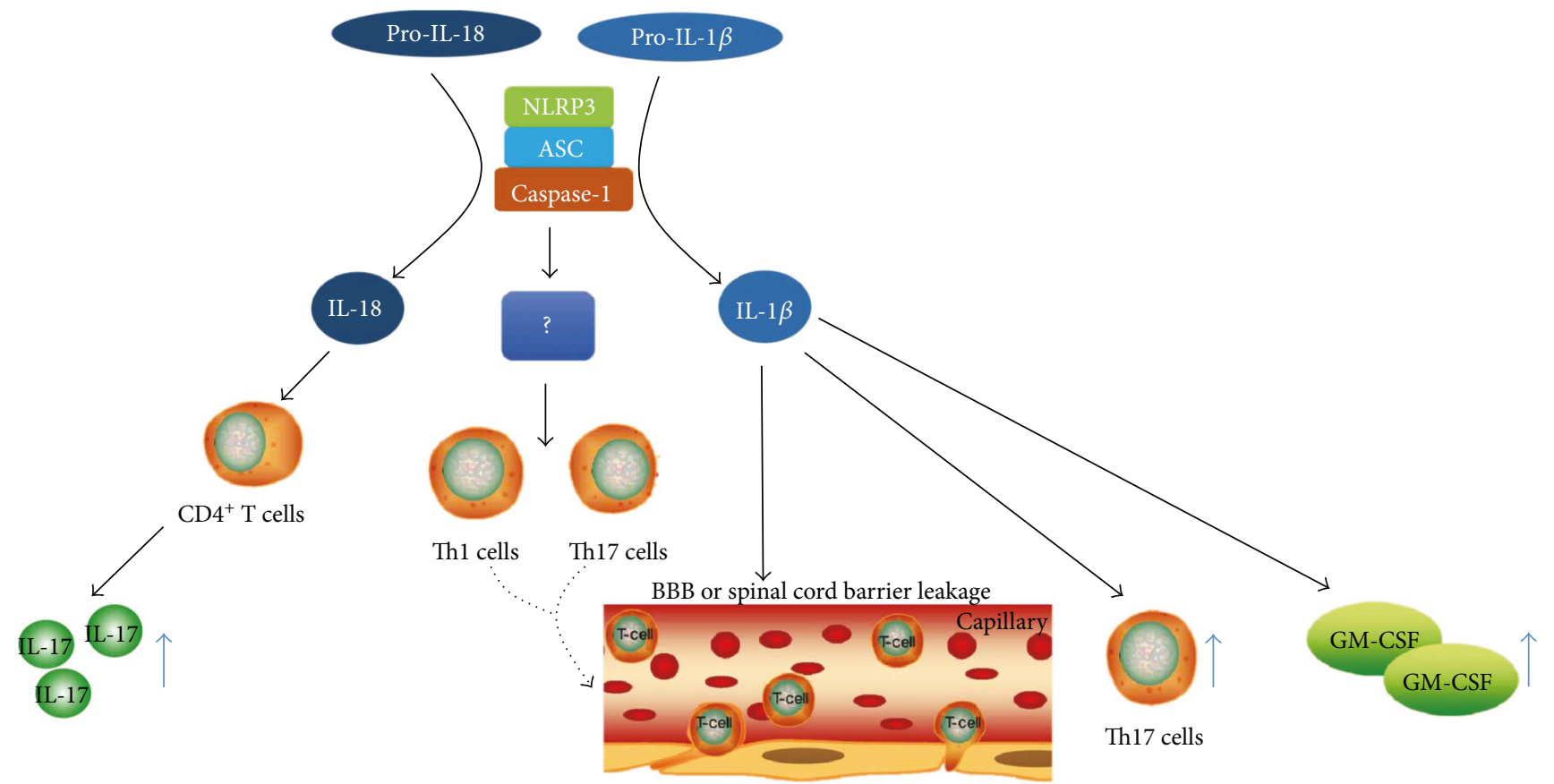

FIGURE 1: Inflammasomes and factors involved in the pathogenesis of MS/EAE. NLRP3 inflammasomes convert pro-IL-1 $\beta$ and pro-IL-18 to IL-1 $\beta$ and IL-18. IL-18 stimulates CD4 ${ }^{+}$T cells to produce IL-17; NLRP3 inflammasomes contribute to T cell chemotactic activity in the CNS; IL- $1 \beta$ induces the differentiation of Th17 cells and promotes them infiltrate into the CNS; IL- $1 \beta$ also induces the production of GM-CSF, which is an important factor in T cell encephalitogenicity. IL-1 $\beta$ : interleukin-1 $\beta$; IL-18: interleukin-18; IL-17: interleukin-17; NLRP3: NOD-like receptor pyrin domain-containing 3; ASC, apoptosis-associated speck-like protein containing a caspase recruitment domain; BBB: blood-brain barrier; GM-CSF: granulocyte-macrophage colony-stimulating factor.

Interestingly, inflammasomes have been evidenced to excrete exosomes acting on nearby macrophages and activating the NF- $\kappa \mathrm{B}$ signal pathway, which may enhance the immune response in autoimmune diseases [83]. These findings regarding the mechanism of inflammasomes involved in inflammation may give new insights into the pathogenesis of MS/EAE. The inflammasomes and factors involved in MS/EAE are shown in Figure 1.

\section{Inflammasomes and the Role of IFN $\gamma$ and IFN $\beta$ in EAE}

According to Inoue et al., EAE can be of two types: type A which is NLRP3-dependent and type B, which is NLRP3independent and resistant to interferon- $\beta$ (IFN $\beta$ ) treatment [84]. Type B EAE accounts for one-third of all EAE animals [85]. The two subtypes are amenable to alteration during EAE development.

IFN $\beta$ is effective in relapsing-remitting multiple sclerosis (RRMS) via inhibition of NLRP3 [84, 86]. Type I interferon was shown to inhibit NLRP1/NLRP3 inflammasome and then reduce the expression levels of pro-IL-1 $\beta$ /pro-IL-18 [86]. Besides, binding of IFN $\beta$ with IFN receptor I on antigen-presenting cells (APCs) inhibits suppression of cytokine signaling (SOCS), which can downregulate a member of the Rho family of GTPases, Rac1-guanosine triphosphate (Rac1-GTP), through SOCS-1 and induce generation of reactive oxygen species (ROS) [84]. The increase in ROS level is conducive to activation of inflammasomes. However, these mechanisms do not work on NLRC4 inflammasomes. Moreover, there is proof of involvement of the other inflammasome components in the pathogenesis of MS: NOD2 gene polymorphism rs5743291 was shown to activate Th2 and Th17 cells in patients with MS [87]. Further, targeting of NOD2 pathways with a NOD2-activating agent, MIS416, was shown to modulate the $\mathrm{Th}$ response and alleviate EAE [88].

In a study by Noroozi et al., MS patients treated with IFN $\beta$ experienced a decrease in plasma IL- $1 \beta$ levels as well as the expressions of NLRP3, NLRC4, and AIM2 in peripheral blood mononuclear cells [89]. Similar results have been reported from a study by Malhotra et al.: MS patients who responded well to $\operatorname{IFN} \beta$ showed lower mRNA levels of NLRP3 and IL-1 $\beta$ as compared to their pretreatment levels; conversely, nonresponders experienced upregulation of NLRP3 and IL- $1 \beta$ mRNA levels after three months of treatment with IFN $\beta$ [90]. The underlying mechanism of resistance of the NLRP3 inflammasomeindependent pattern to IFN $\beta$ treatment is not completely understood. However, Inoue et al. [91] have shown that membrane-bound lymphotoxin and the chemokine receptor CXCR are involved in this process and antagonizing these receptors ameliorates NLRP3-independent EAE.

\section{The Targets of Treatment in MS/EAE}

Owing to the key role of inflammasomes in the development of EAE or MS, research on the means to inhibit their function 
is of much clinical relevance. The upstream factors and downstream effectors of inflammasomes are attractive therapeutic targets in the context of EAE/MS. JC-171, a hydroxyl sulfonamide analogue, which is a selective NLRP3 inflammasome inhibitor, has been shown to exhibit preventive and therapeutic effects in the EAE setting [92]. In a study by Coll et al. [93], MCC950 (a diarylsulfonylurea-containing compound that inhibits IL-1 $\beta$ ) was shown to specifically inhibit canonical and noncanonical NLRP3 activation in EAE. Moreover, as Gao et al. [81] described that CD47-Fc fusion protein, the inhibitor of $\mathrm{CD} 47$, which is capable of inducing NO production that suppresses inflammasome activationinduced IL-1 $\beta$ expression, could also prevent and ameliorate EAE. Similarly, cladribine, an adenosine deaminase inhibitor, was shown to suppress excitatory postsynaptic currents induced by IL- $1 \beta$, which has been proven to be one of the mechanisms for treatment of MS [94]. Furthermore, NLRP3 is involved in mediating the therapeutic effect of prednisone [95], cannabinoid receptor 2 (CB2R) [96], and periodontal ligament stem cells [97] in EAE.

\section{Inflammasomes in Alzheimer's Disease}

Alzheimer's disease $(\mathrm{AD})$ is a neurodegenerative disease characterized by progressive cognitive impairment. It accounts for $50 \%$ to $70 \%$ of cases with dementia in the elderly [98] and is viewed as one of the great health-care challenges of the 21st century [99]. However, there is no effective cure to halt the progress of this disease [99]. $\mathrm{AD}$ is pathologically characterized by $\mathrm{A} \beta$ deposit. The $\mathrm{A} \beta$ deposit and damage-associated molecular pattern molecules (DAMPs) released by the subsequent neuronal injury are sensed by inflammasomes, which initiates an innate immune response $[100,101]$. The messenger RNA (mRNA) levels of the NLRP1 and NLRP3 components increase in $A D$ [102]. NLRP1 induces caspase- 1 and caspase- 6 , and this pathway is involved in the progression of $\mathrm{AD}$ [103]. In addition to exhibiting lower caspase- 1 and IL- $1 \beta$ activity levels and enhanced $\mathrm{A} \beta$ clearance, $\mathrm{NLRP}^{-1-}$ mice display better memory than do NLRP3 wild-type mice. Moreover, knocking down NLRP3 promotes M1-type microglial bias to the M2 type. This helps in $\mathrm{A} \beta$ clearance and tissue remodeling in the APP/PS1 model as M2-type microglia are efficient at phagocytosis [104]. The mechanism of activation of NLRP3 is yet to be clarified; however, in microglia, NLRP3 inflammasomes were shown to be activated not only by $\mathrm{A} \beta$ via the TLR4-MyD88-NF- $\kappa \mathrm{B}$ pathway in microglia but also by P2X7R as in the EAE model and cathepsin B (CTSB). In addition, NLRP10, another NOD-like receptor, has been shown to attenuate $\mathrm{A} \beta$-induced caspase- 1 activation and IL- $1 \beta$ release [105].

The fact that the overexpression of the effectors of inflammasomes, IL- $1 \beta$ and IL-18, initiates the inflammatory process in $\mathrm{AD}$ patients verifies the association between inflammasome and $\mathrm{AD}[106,107]$. Kitazawa et al. demonstrated that the IL- $1 \beta$ signal cascade is an important pathogenic factor of $\mathrm{AD}$; its blockade was shown to ameliorate pathological changes in a mouse model of $\mathrm{AD}$ [108]. In a study by Craft et al., knocking out the IL- $1 \beta$ receptor antagonist in a mouse model of $\mathrm{AD}$ was shown to aggravate the neuropathological sequelae [109]. The above-mentioned investigations indicate that inhibition of inflammasome activation might be a potential therapeutic target for $\mathrm{AD}$. The inflammasomes involved in $\mathrm{AD}$ are shown in Figure 2.

\section{Inflammasomes in Parkinson's Disease}

Parkinson's disease (or paralysis agitans) is a common neurodegenerative disorder, which is characterized by loss of dopaminergic neurons [110] and aggregation of the $\alpha$ synuclein deposit [111]. Activation of inflammasomes and elevation of serum caspase-1 and IL-1 $\beta$ levels have been demonstrated in nigrostriatal DA regions of the PD mouse model as well as in the brain and cerebrospinal fluid of $\mathrm{PD}$ patients [112-114]. Inflammasomes could be activated by oxidative stress and excessive activated microglia, both of which play an important role in the pathogenesis of PD. To be specific, oxidative stress from ROS activates NLRP3 through c-Abl kinase or upregulates CTSB activity in microglial cells $[115,116]$. Additionally, cyclin-dependent kinase 5 $(\mathrm{Cdk} 5)$ is also an essential factor for activation of inflammasomes in neurons [114]. Caspase-1- and caspase-3-related apoptotic cell death is a crucial link, through which epidemiological risk factors such as MPP (+), paraquat, dieldrin, and salsolinol can cause PD $[117,118]$. Furthermore, caspase-1 could directly cleave $\alpha$-synuclein into a highly aggregationprone variant, which subsequently forms aggregated $\alpha$-synuclein and assaults neurons [119]. Noteworthily, despite of the correlation between caspase- 1 and PD, caspase- 1 may not be the determining factor of dopaminergic neuronal death in vitro, or the efficacy of caspase- 1 inhibitors may depend on the extent of apoptotic stress [120]. Specifically, caspase1 inhibitors did not improve the survival of grafted dopaminergic neurons in 1-methyl-4-phenyl-1,2,3,6-tetrahydropyridine- (MPTP-) induced PD models [120], and caspase-1 inhibitors could not prevent dopaminergic neuronal death in MPTP parkinsonian mice [121].

The function of NLRP3 and caspase-1 is closely related to $\alpha$-synuclein, the pathogenic factor of PD. $\alpha$-Synuclein activates the toll-like receptor 2 (TLR2) that promotes the assembly of NLRP3 [122] and induces synthesis of IL-1 $\beta$ [123]. The increase in IL- $1 \beta$ expression level induces production of ROS and release of CTSB, which in turn activates NLRP3 $[115,123]$. Besides, $\alpha$-synuclein was shown to promote both TLR4/NF- $\kappa$ B and NLRP3/caspase-1 signals in adult neural stem cells (ANSCs), and both NLRP3 knockdown and caspase-1 deficiency reverse the antiproliferation effect of $\alpha$-synuclein on ANSCs [39]. In terms of the treatment of PD, pharmacological inhibitions for inflammasome activation-related molecules, such as caspase-1, microRNA-7, CTSB, c-Abl, and Cdk5, may open up novel therapeutic avenues. The inflammasomes involved in PD are shown in Figure 2.

\section{Closing Remarks}

Inflammasomes are supramolecular signaling complexes involved in the inflammatory process. They consist of three 


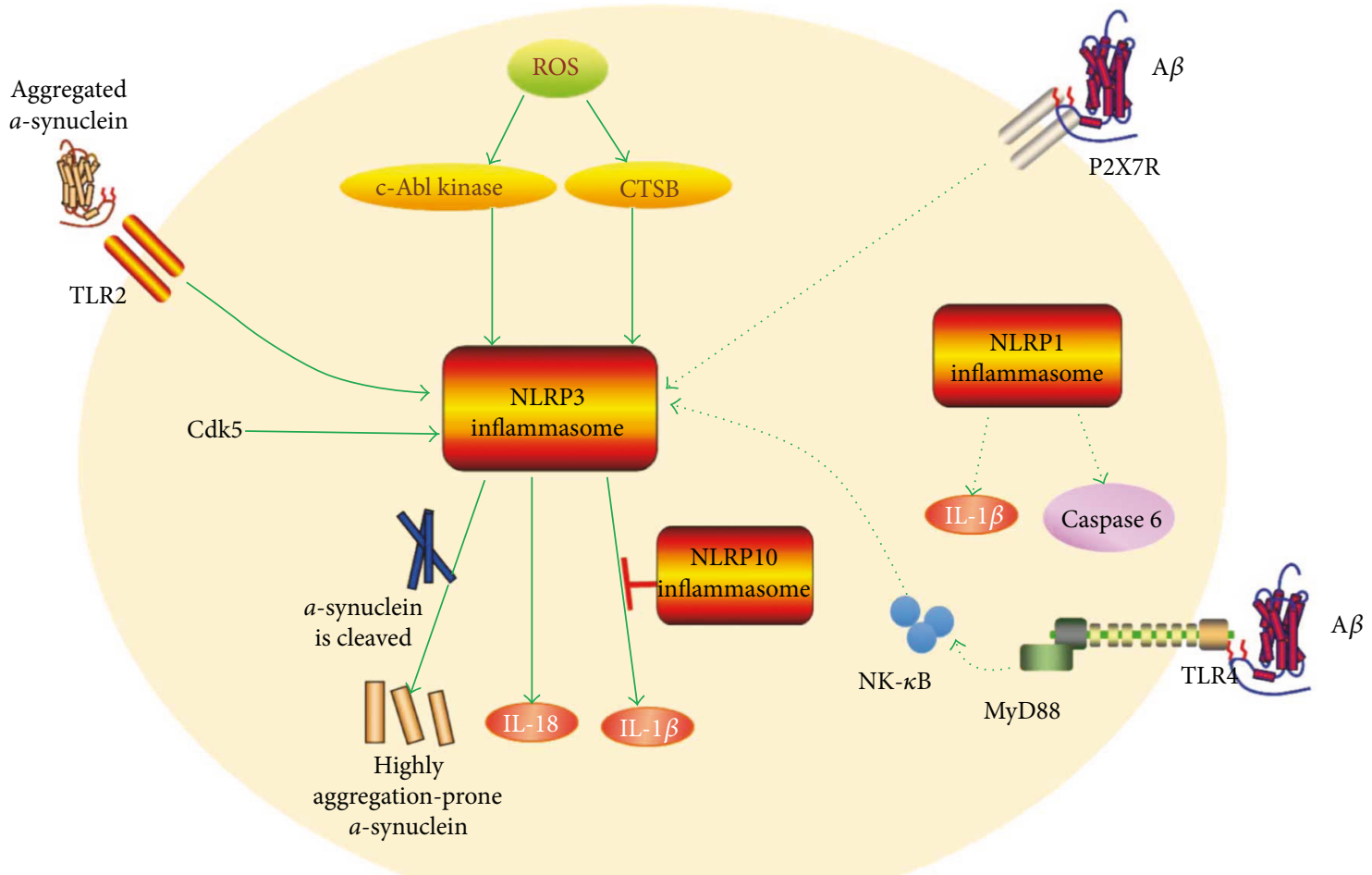

FIgURe 2: Schematic illustration of the role of inflammasomes in Parkinson's disease and Alzheimer's disease. NLRP1 induces IL-1 $\beta$ production and caspase 6 activation, which are factors involved in the progress of AD. A $\beta$ activates NLRP3 inflammasomes via the P2X7R receptor or TLR4-MyD88-NF- $\kappa$ B pathway, $\alpha$-synuclein activates the toll-like receptor 2 (TLR2) which promotes the assembly of NLRP3 and induces IL- $1 \beta$ synthesis, ROS activates NLRP3 through c-Abl kinase or upregulates CTSB activity, Cdk5 could activate NLRP3 inflammasome, caspase- 1 could cleave $\alpha$-synuclein into a highly aggregation-prone specie, and NLRP10 attenuates A $\beta$-induced caspase 1 activation and IL-1 $\beta$ release. PD: Parkinson's disease; AD: Alzheimer's disease; TLR2: toll-like receptor 2; IL-1 $\beta$ : interleukin-1 $\beta$; CTSB: cathepsin B; Cdk5: cyclin-dependent kinase 5; ROS: reactive oxygen species.

components: sensors, ASC, and caspases. There are subvariants of sensors and caspases, such as NLRP1, NLRP3, caspase- 1 , and caspase- 4 , marking variable inflammasomes with different biological functions. Most of the inflammasomes contribute to the development of neuroimmune and neurodegenerative diseases such as the NLRP3 inflammasome, while some have anti-inflammatory properties such as NLRX1 inflammasome and NLRP12 inflammasome. In the pathogenesis of MS/EAE, inflammasomes promote Th1 and Th17 cells migrating into CNS. Furthermore, they enhance the immune response in EAE by secreting exosomes to act on nearby macrophages. In patients and animal models of $\mathrm{AD}$ and $\mathrm{PD}$, the component of inflammasomes, such as caspase- 1 , and the effector IL- $1 \beta$ and IL-18, all can aggravate the $\mathrm{A} \beta$ - or $\alpha$-synuclein-induced pathological process. Though substantial evidence has proved the vital roles of inflammasomes, the exact mechanism underlying inflammatory reactions in these disorders is yet to be fully understood. Theoretically, inflammasome antagonists may exhibit a protective effect on the patients with neuroimmune or neurodegenerative disorders via multiple pathways. Nevertheless, the efficacy of inflammasome-targeted therapies still needs further investigations. In addition, the exact pathogenesis of NLRP3-independent MS is still unclear.
Finally, the most reported inflammasomes involved in the pathogenesis of neuroimmune and neurodegenerative diseases are NLRP3 and NLRP1; whether other inflammasomes are potential important factors contributing to these disorders is worth studying in the future.

\section{Abbreviations}

AD: $\quad$ Alzheimer's disease

ALRs: $\quad$ AIM2-like receptors

ANSCs: Adult neural stem cells

APCs: Antigen-presenting cells

ASC: $\quad$ Apoptosis-associated speck-like protein containing a caspase recruitment domain

ATP: $\quad$ Adenosine triphosphate

CARD: Caspase recruitment domain

CB2R: $\quad$ Cannabinoid receptor 2

CNS: $\quad$ Central nervous system

CPZ: $\quad$ Chlorpromazine

CSF: $\quad$ Cerebrospinal fluid

DAMPs: Damage-associated molecular patterns

EAE: Experimental autoimmune encephalomyelitis

IAP: $\quad$ Integrin-associated protein

IFN $\beta$ : $\quad$ Interferon- $\beta$ 


$\begin{array}{ll}\text { IL-1 } \beta \text { : } & \text { Interleukin-1 } \beta \\ \text { mRNA: } & \text { Messenger RNA } \\ \text { MS: } & \text { Multiple sclerosis } \\ \text { NLRs: } & \text { NOD-like receptors } \\ \text { NLRP3: } & \text { NOD-like receptor pyrin domain-containing } 3 \\ \text { NO: } & \text { Nitric oxide } \\ \text { NOD: } & \text { Nucleotide-binding oligomerization domain } \\ \text { PAMPs: } & \text { Pathogen-associated molecular patterns } \\ \text { PD: } & \text { Parkinson's disease } \\ \text { POM-1: } & \text { Polyoxotungstate-1 } \\ \text { PYD: } & \text { Pyrin domain } \\ \text { Rac1-GTP: } & \text { Rac1-guanosine triphosphate } \\ \text { ROS: } & \text { Reactive oxygen species } \\ \text { ROT: } & \text { Rotenone } \\ \text { RRMS: } & \text { Relapsing-remitting multiple sclerosis } \\ \text { TLRs: } & \text { Toll-like receptors } \\ \text { TNF: } & \text { Tumor necrosis factor } \\ \text { TNFAIP3: } & \text { Tumor necrosis factor } \alpha \text {-induced protein } 3 \\ \text { TRAF: } & \text { TNF receptor-associated factor } \\ \text { SOCS: } & \text { Suppressor of cytokine signaling. }\end{array}$

\section{Conflicts of Interest}

The authors declare that they have no competing interests.

\section{Acknowledgments}

This study was supported by grants from The First Hospital, Jilin University, Changchun, China, and from the National Natural Science Foundation (nos. 8167050314, 81471216, $81671186,81671177,31600820$, and 2017030) as well as from the Swedish Research Council (K2013-66X-22337-01-3 and project with 2015-03005).

\section{References}

[1] M. Lamkanfi and V. M. Dixit, "Mechanisms and functions of inflammasomes," Cell, vol. 157, no. 5, pp. 1013-1022, 2014.

[2] S. E. Adamczak, J. P. de Rivero Vaccari, G. Dale et al., "Pyroptotic neuronal cell death mediated by the AIM2 inflammasome," Journal of Cerebral Blood Flow \& Metabolism, vol. 34, no. 4, pp. 621-629, 2014.

[3] U. K. Hanisch, "Microglia as a source and target of cytokines," Glia, vol. 40, no. 2, pp. 140-155, 2002.

[4] J. Minkiewicz, J. P. de Rivero Vaccari, and R. W. Keane, "Human astrocytes express a novel NLRP2 inflammasome," Glia, vol. 61, no. 7, pp. 1113-1121, 2013.

[5] M. Xiang, X. Shi, Y. Li et al., "Hemorrhagic shock activation of NLRP3 inflammasome in lung endothelial cells," The Journal of Immunology, vol. 187, no. 9, pp. 4809-4817, 2011.

[6] C. Basset, J. Holton, R. O’Mahony, and I. Roitt, "Innate immunity and pathogen-host interaction," Vaccine, vol. 21, Supplement 2, pp. S12-S23, 2003.

[7] T. Fernandes-Alnemri, J. W. Yu, P. Datta, J. Wu, and E. S. Alnemri, "AIM2 activates the inflammasome and cell death in response to cytoplasmic DNA," Nature, vol. 458, no. 7237, pp. 509-513, 2009.

[8] A. Lu, V. G. Magupalli, J. Ruan et al., "Unified polymerization mechanism for the assembly of ASC-dependent inflammasomes," Cell, vol. 156, no. 6, pp. 1193-1206, 2014.
[9] L. Sborgi, F. Ravotti, V. P. Dandey et al., "Structure and assembly of the mouse ASC inflammasome by combined NMR spectroscopy and cryo-electron microscopy," Proceedings of the National Academy of Sciences of the United States of America, vol. 112, no. 43, pp. 13237-13242, 2015.

[10] I. Jorgensen and E. A. Miao, "Pyroptotic cell death defends against intracellular pathogens," Immunological Reviews, vol. 265, no. 1, pp. 130-142, 2015.

[11] C. E. Sutton, S. J. Lalor, C. M. Sweeney, C. F. Brereton, E. C. Lavelle, and K. H. G. Mills, "Interleukin-1 and IL-23 induce innate IL-17 production from $\gamma \delta$ T cells, amplifying Th17 responses and autoimmunity," Immunity, vol. 31, no. 2, pp. 331-341, 2009.

[12] S. Karakas Celik, Z. S. Öz, A. Dursun et al., "Interleukin 18 gene polymorphism is a risk factor for multiple sclerosis," Molecular Biology Reports, vol. 41, no. 3, pp. 16531658, 2014.

[13] B. Faustin, L. Lartigue, J. M. Bruey et al., "Reconstituted NALP1 inflammasome reveals two-step mechanism of caspase-1 activation," Molecular Cell, vol. 25, no. 5, pp. 713-724, 2007.

[14] A. R. Shenoy, D. A. Wellington, P. Kumar et al., "GBP5 promotes NLRP3 inflammasome assembly and immunity in mammals," Science, vol. 336, no. 6080, pp. 481-485, 2012.

[15] Y. Qu, S. Misaghi, A. Izrael-Tomasevic et al., "Phosphorylation of NLRC4 is critical for inflammasome activation," Nature, vol. 490, no. 7421, pp. 539-542, 2012.

[16] G. I. Vladimer, D. Weng, S. W. M. Paquette et al., "The NLRP12 inflammasome recognizes Yersinia pestis," Immunity, vol. 37, no. 1, pp. 96-107, 2012.

[17] S. E. Warren, A. Armstrong, M. K. Hamilton et al., "Cutting edge: cytosolic bacterial DNA activates the inflammasome via Aim2," The Journal of Immunology, vol. 185, no. 2, pp. 818-821, 2010.

[18] D. Kwon, E. Park, and S. J. Kang, "Stimulator of IFN genesmediated DNA-sensing pathway is suppressed by NLRP3 agonists and regulated by mitofusin 1 and TBC1D15, mitochondrial dynamics mediators," The FASEB Journal, vol. 31, no. 11, pp. 4866-4878, 2017.

[19] C. Antonopoulos, H. M. Russo, C. El Sanadi et al., "Caspase-8 as an effector and regulator of NLRP3 inflammasome signaling," The Journal of Biological Chemistry, vol. 290, no. 33, pp. 20167-20184, 2015.

[20] N. Kayagaki, S. Warming, M. Lamkanfi et al., "Noncanonical inflammasome activation targets caspase-11," Nature, vol. 479, no. 7371, pp. 117-121, 2011.

[21] T. K. Eitas, W. C. Chou, H. Wen et al., "The nucleotidebinding leucine-rich repeat (NLR) family member NLRX1 mediates protection against experimental autoimmune encephalomyelitis and represses macrophage/microgliainduced inflammation," Journal of Biological Chemistry, vol. 289, no. 7, pp. 4173-4179, 2014.

[22] I. C. Allen, E. M. E. TeKippe, R. M. T. Woodford et al., "The NLRP3 inflammasome functions as a negative regulator of tumorigenesis during colitis-associated cancer," Journal of Experimental Medicine, vol. 207, no. 5, pp. 1045-1056, 2010.

[23] C. A. Yang and B. L. Chiang, "Inflammasomes and human autoimmunity: a comprehensive review," Journal of Autoimmunity, vol. 61, pp. 1-8, 2015.

[24] W. Sha, H. Mitoma, S. Hanabuchi et al., "Human NLRP3 inflammasome senses multiple types of bacterial RNAs," 
Proceedings of the National Academy of Sciences of the United States of America, vol. 111, no. 45, pp. 16059-16064, 2014.

[25] S. Mariathasan, D. S. Weiss, K. Newton et al., "Cryopyrin activates the inflammasome in response to toxins and ATP," Nature, vol. 440, no. 7081, pp. 228-232, 2006.

[26] F. Martinon, V. Pétrilli, A. Mayor, A. Tardivel, and J. Tschopp, "Gout-associated uric acid crystals activate the NALP3 inflammasome," Nature, vol. 440, no. 7081, pp. 237-241, 2006.

[27] V. Hornung, F. Bauernfeind, A. Halle et al., "Silica crystals and aluminum salts activate the NALP3 inflammasome through phagosomal destabilization," Nature Immunology, vol. 9, no. 8, pp. 847-856, 2008.

[28] B. N. Martin, C. Wang, C. J. Zhang et al., "T cell-intrinsic ASC critically promotes $\mathrm{T}_{\mathrm{H}} 17$-mediated experimental autoimmune encephalomyelitis," Nature Immunology, vol. 17, no. 5, pp. 583-592, 2016.

[29] S. E. Adamson and N. Leitinger, "The role of pannexin1 in the induction and resolution of inflammation," FEBS Letters, vol. 588, no. 8, pp. 1416-1422, 2014.

[30] J. P. de Rivero Vaccari, D. Bastien, G. Yurcisin et al., "P2X receptors influence inflammasome activation after spinal cord injury," The Journal of Neuroscience, vol. 32, no. 9, pp. 3058-3066, 2012.

[31] C. Fan, X. Zhao, X. Guo, X. Cao, and J. Cai, "P2X4 promotes interleukin-1 $\beta$ production in osteoarthritis via NLRP1," Molecular Medicine Reports, vol. 9, no. 1, pp. 340344, 2014.

[32] A. Babelova, K. Moreth, W. Tsalastra-Greul et al., "Biglycan, a danger signal that activates the NLRP3 inflammasome via toll-like and P2X receptors," Journal of Biological Chemistry, vol. 284, no. 36, pp. 24035-24048, 2009.

[33] S. Chen and B. Sun, "Negative regulation of NLRP3 inflammasome signaling," Protein \& Cell, vol. 4, no. 4, pp. 251258, 2013.

[34] J. M. Bruey, N. Bruey-Sedano, F. Luciano et al., "Bcl-2 and $\mathrm{Bcl}-\mathrm{X}_{\mathrm{L}}$ regulate proinflammatory caspase-1 activation by interaction with NALP1," Cell, vol. 129, no. 1, pp. 45$56,2007$.

[35] L. V. Walle, N. van Opdenbosch, P. Jacques et al., "Negative regulation of the NLRP3 inflammasome by A20 protects against arthritis," Nature, vol. 512, no. 7512, pp. 69-73, 2014.

[36] T. Eigenbrod, K. A. Bode, and A. H. Dalpke, "Early inhibition of IL- $1 \beta$ expression by IFN- $\gamma$ is mediated by impaired binding of NF- $\kappa \mathrm{B}$ to the IL- $1 \beta$ promoter but is independent of nitric oxide," The Journal of Immunology, vol. 190, no. 12, pp. 6533-6541, 2013.

[37] F. Q. Kong, B. Z. Ye, L. Lin, X. Cai, W. Huang, and Z. Huang, "Atorvastatin suppresses NLRP3 inflammasome activation via TLR4/MyD88/NF- $\kappa$ B signaling in PMA-stimulated THP1 monocytes," Biomedicine \& Pharmacotherapy, vol. 82, pp. 167-172, 2016.

[38] F. Bauernfeind, A. Rieger, F. A. Schildberg, P. A. Knolle, J. L. Schmid-Burgk, and V. Hornung, "NLRP3 inflammasome activity is negatively controlled by miR-223," The Journal of Immunology, vol. 189, no. 8, pp. 4175-4181, 2012.

[39] Z. Fan, M. Lu, C. Qiao, Y. Zhou, J. H. Ding, and G. Hu, "MicroRNA-7 enhances subventricular zone neurogenesis by inhibiting NLRP3/caspase-1 axis in adult neural stem cells," Molecular Neurobiology, vol. 53, no. 10, pp. 70577069, 2016
[40] G. Guarda, C. Dostert, F. Staehli et al., "T cells dampen innate immune responses through inhibition of NLRP1 and NLRP3 inflammasomes," Nature, vol. 460, no. 7252, pp. 269-273, 2009.

[41] V. Beynon, F. J. Quintana, and H. L. Weiner, "Activated human $\mathrm{CD} 4+\mathrm{CD} 45 \mathrm{RO}+$ memory T-cells indirectly inhibit NLRP3 inflammasome activation through downregulation of P2X7R signalling," PLoS One, vol. 7, no. 6, article e39576, 2012.

[42] M. Saleh, J. C. Mathison, M. K. Wolinski et al., "Enhanced bacterial clearance and sepsis resistance in caspase-12deficient mice," Nature, vol. 440, no. 7087, pp. 1064-1068, 2006.

[43] G. Pimenta-dos-Reis, E. J. L. Torres, P. G. Quintana et al., "POM-1 inhibits P2 receptors and exhibits antiinflammatory effects in macrophages," Purinergic Signal, vol. 13, no. 4, pp. 611-627, 2017.

[44] Z. Jian, S. Ding, H. Deng et al., "Probenecid protects against oxygen-glucose deprivation injury in primary astrocytes by regulating inflammasome activity," Brain Research, vol. 1643, pp. 123-129, 2016.

[45] W. R. Silverman, J. P. de Rivero Vaccari, S. Locovei et al., "The pannexin 1 channel activates the inflammasome in neurons and astrocytes," Journal of Biological Chemistry, vol. 284, no. 27, pp. 18143-18151, 2009.

[46] E. Bettelli, "Building different mouse models for human MS," Annals of the New York Academy of Sciences, vol. 1103, no. 1, pp. 11-18, 2007.

[47] A. Dumas, N. Amiable, J. P. de Rivero Vaccari et al., "The inflammasome pyrin contributes to pertussis toxin-induced IL- $1 \beta$ synthesis, neutrophil intravascular crawling and autoimmune encephalomyelitis," PLoS Pathogens, vol. 10, no. 5, article e1004150, 2014.

[48] R. Furlan, M. Filippi, A. Bergami et al., "Peripheral levels of caspase-1 mRNA correlate with disease activity in patients with multiple sclerosis; a preliminary study," Journal of Neurology, Neurosurgery, \& Psychiatry, vol. 67, no. 6, pp. 785-788, 1999.

[49] D. Gris, Z. Ye, H. A. Iocca et al., "NLRP3 plays a critical role in the development of experimental autoimmune encephalomyelitis by mediating Th1 and Th17 responses," The Journal of Immunology, vol. 185, no. 2, pp. 974-981, 2010.

[50] F. Martinon and J. Tschopp, "Inflammatory caspases and inflammasomes: master switches of inflammation," Cell Death \& Differentiation, vol. 14, no. 1, pp. 10-22, 2007.

[51] J. P. de Rivero Vaccari, G. Lotocki, A. E. Marcillo, W. D. Dietrich, and R. W. Keane, "A molecular platform in neurons regulates inflammation after spinal cord injury," The Journal of Neuroscience, vol. 28, no. 13, pp. 3404-3414, 2008.

[52] L. Franchi, T. Eigenbrod, R. Muñoz-Planillo, and G. Nuñez, "The inflammasome: a caspase-1-activation platform that regulates immune responses and disease pathogenesis," Nature Immunology, vol. 10, no. 3, pp. 241-247, 2009.

[53] A. M. Soulika, E. Lee, E. McCauley, L. Miers, P. Bannerman, and D. Pleasure, "Initiation and progression of axonopathy in experimental autoimmune encephalomyelitis," The Journal of Neuroscience, vol. 29, no. 47, pp. 14965-14979, 2009.

[54] R. Aryanpour, P. Pasbakhsh, K. Zibara et al., "Progesterone therapy induces an M1 to M2 switch in microglia phenotype 
and suppresses NLRP3 inflammasome in a cuprizoneinduced demyelination mouse model," International Immunopharmacology, vol. 51, pp. 131-139, 2017.

[55] Y. Shinar, A. Livneh, Y. Villa et al., "Common mutations in the familial Mediterranean fever gene associate with rapid progression to disability in non-Ashkenazi Jewish multiple sclerosis patients," Genes \& Immunity, vol. 4, no. 3, pp. 197-203, 2003.

[56] A. Unal, A. Dursun, U. Emre, N. F. Tascilar, and H. Ankarali, "Evaluation of common mutations in the Mediterranean fever gene in multiple sclerosis patients: is it a susceptibility gene?," Journal of the Neurological Sciences, vol. 294, no. 1-2, pp. 38-42, 2010.

[57] G. Yahalom, S. Kivity, M. Lidar et al., "Familial Mediterranean fever (FMF) and multiple sclerosis: an association study in one of the world's largest FMF cohorts," European Journal of Neurology, vol. 18, no. 9, pp. 1146-1150, 2011.

[58] E. Schuh, P. Lohse, B. Ertl-Wagner et al., "Expanding spectrum of neurologic manifestations in patients with NLRP3 low-penetrance mutations," Neurology - Neuroimmunology Neuroinflammation, vol. 2, no. 4, article e109, 2015.

[59] S. Compeyrot-Lacassagne, T. A. Tran, S. Guillaume-Czitrom, I. Marie, and I. Kone-Paut, "Brain multiple sclerosis-like lesions in a patient with Muckle-Wells syndrome," Rheumatology, vol. 48, no. 12, pp. 1618-1619, 2009.

[60] T. Lequerre, O. Vittecoq, P. Saugier-Veber et al., "A cryopyrin-associated periodic syndrome with joint destruction," Rheumatology, vol. 46, no. 4, pp. 709-714, 2007.

[61] L. Fiorentino, C. Stehlik, V. Oliveira, M. E. Ariza, A. Godzik, and J. C. Reed, "A novel PAAD-containing protein that modulates NF- $\kappa$ B induction by cytokines tumor necrosis factor- $\alpha$ and interleukin-1 $\beta$," Journal of Biological Chemistry, vol. 277, no. 38, pp. 35333-35340, 2002.

[62] Z. Ye, J. D. Lich, C. B. Moore, J. A. Duncan, K. L. Williams, and J. P. Y. Ting, "ATP binding by monarch-1/NLRP12 is critical for its inhibitory function," Molecular and Cellular Biology, vol. 28, no. 5, pp. 1841-1850, 2008.

[63] I. C. Allen, J. E. Wilson, M. Schneider et al., "NLRP12 suppresses colon inflammation and tumorigenesis through the negative regulation of noncanonical NF- $\kappa \mathrm{B}$ signaling," Immunity, vol. 36, no. 5, pp. 742-754, 2012.

[64] M. Gharagozloo, T. M. Mahvelati, E. Imbeault et al., "The nod-like receptor, Nlrp12, plays an anti-inflammatory role in experimental autoimmune encephalomyelitis," Journal of Neuroinflammation, vol. 12, no. 1, p. 198, 2015.

[65] M. A. Gavrilin, D. H. A. Abdelaziz, M. Mostafa et al., "Activation of the pyrin inflammasome by intracellular Burkholderia cenocepacia," The Journal of Immunology, vol. 188, no. 7, pp. 3469-3477, 2012.

[66] J. J. Chae, H. D. Komarow, J. Cheng et al., "Targeted disruption of pyrin, the FMF protein, causes heightened sensitivity to endotoxin and a defect in macrophage apoptosis," Molecular Cell, vol. 11, no. 3, pp. 591-604, 2003.

[67] M. Prins, C. Eriksson, A. Wierinckx et al., "Interleukin-1 $\beta$ and interleukin-1 receptor antagonist appear in grey matter additionally to white matter lesions during experimental multiple sclerosis," PLoS One, vol. 8, no. 12, article e83835, 2013.

[68] I. D. Vainchtein, J. Vinet, N. Brouwer et al., "In acute experimental autoimmune encephalomyelitis, infiltrating macrophages are immune activated, whereas microglia remain immune suppressed," Glia, vol. 62 , no. 10, pp. $1724-$ 1735, 2014.

[69] A. E. Russi, M. E. Walker-Caulfield, Y. Guo, C. F. Lucchinetti, and M. A. Brown, "Meningeal mast cell-T cell crosstalk regulates T cell encephalitogenicity," Journal of Autoimmunity, vol. 73, pp. 100-110, 2016.

[70] S. M. Burm, L. A. N. Peferoen, E. A. Zuiderwijk-Sick et al., "Expression of IL- $1 \beta$ in rhesus EAE and MS lesions is mainly induced in the CNS itself," Journal of Neuroinflammation, vol. 13, no. 1, p. 138, 2016.

[71] A. G. Kermode, A. J. Thompson, P. Tofts et al., "Breakdown of the blood-brain barrier precedes symptoms and other MRI signs of new lesions in multiple sclerosis: pathogenetic and clinical implications," Brain, vol. 113, no. 5, pp. 1477 1489, 1990.

[72] A. T. Argaw, Y. Zhang, B. J. Snyder et al., "IL-1 $\beta$ regulates blood-brain barrier permeability via reactivation of the hypoxia-angiogenesis program," The Journal of Immunology, vol. 177, no. 8, pp. 5574-5584, 2006.

[73] L. P. Shornick, A. K. Bisarya, and D. D. Chaplin, "IL- $1 \beta$ is essential for Langerhans cell activation and antigen delivery to the lymph nodes during contact sensitization: evidence for a dermal source of IL-1 $\beta$," Cellular Immunology, vol. 211, no. 2, pp. 105-112, 2001.

[74] A. E. Russi, M. E. Walker-Caulfield, and M. A. Brown, "Mast cell inflammasome activity in the meninges regulates EAE disease severity," Clinical Immunology, 2016, In press.

[75] Y. Chung, S. H. Chang, G. J. Martinez et al., "Critical regulation of early Th17 cell differentiation by interleukin-1 signaling," Immunity, vol. 30, no. 4, pp. 576-587, 2009.

[76] A. S. Moraes, R. F. O. Paula, F. Pradella et al., "The suppressive effect of IL-27 on encephalitogenic Th17 cells induced by multiwalled carbon nanotubes reduces the severity of experimental autoimmune encephalomyelitis," CNS Neuroscience \& Therapeutics, vol. 19, no. 9, pp. 682-687, 2013.

[77] S. J. Lalor, L. S. Dungan, C. E. Sutton, S. A. Basdeo, J. M. Fletcher, and K. H. G. Mills, "Caspase-1-processed cytokines IL- $1 \beta$ and IL- 18 promote IL-17 production by $\gamma \delta$ and CD 4 T cells that mediate autoimmunity," The Journal of Immunology, vol. 186, no. 10, pp. 5738-5748, 2011.

[78] F. Nicoletti, R. di Marco, K. Mangano et al., "Increased serum levels of interleukin-18 in patients with multiple sclerosis," Neurology, vol. 57, no. 2, pp. 342-344, 2001.

[79] J. Zepp, L. Wu, and X. Li, "IL-17 receptor signaling and T helper 17-mediated autoimmune demyelinating disease," Trends in Immunology, vol. 32, no. 5, pp. 232-239, 2011.

[80] M. Inoue, K. L. Williams, M. D. Gunn, and M. L. Shinohara, "NLRP3 inflammasome induces chemotactic immune cell migration to the CNS in experimental autoimmune encephalomyelitis," Proceedings of the National Academy of Sciences of the United States of America, vol. 109, no. 26, pp. 10480 10485, 2012.

[81] Q. Gao, Y. Zhang, C. Han et al., "Blockade of CD47 ameliorates autoimmune inflammation in CNS by suppressing IL-1-triggered infiltration of pathogenic Th17 cells," Journal of Autoimmunity, vol. 69, pp. 74-85, 2016.

[82] S. E. Lutz, E. González-Fernández, J. C. C. Ventura et al., "Contribution of pannexin1 to experimental autoimmune encephalomyelitis," PLoS One, vol. 8, no. 6, article e66657, 2013. 
[83] Y. Zhang, F. Liu, Y. Yuan et al., "Inflammasome-derived exosomes activate NF- $\kappa \mathrm{B}$ signaling in macrophages," Journal of Proteome Research, vol. 16, no. 1, pp. 170-178, 2016.

[84] M. Inoue, K. L. Williams, T. Oliver et al., "Interferon- $\beta$ therapy against EAE is effective only when development of the disease depends on the NLRP3 inflammasome," Science Signaling, vol. 5, no. 225, article ra38, 2012.

[85] B. G. Arnason, "Immunologic therapy of multiple sclerosis," Annual Review of Medicine, vol. 50, no. 1, pp. 291-302, 1999.

[86] G. Guarda, M. Braun, F. Staehli et al., "Type I interferon inhibits interleukin-1 production and inflammasome activation," Immunity, vol. 34, no. 2, pp. 213-223, 2011.

[87] C. J. Hedegaard, C. Enevold, F. Sellebjerg, K. Bendtzen, and C. H. Nielsen, "Variation in NOD2 augments Th2- and Th17 responses to myelin basic protein in multiple sclerosis," PLoS One, vol. 6, no. 5, article e20253, 2011.

[88] M. White, G. Webster, D. O'Sullivan, S. Stone, and A. C. la Flamme, "Targeting innate receptors with MIS416 reshapes Th responses and suppresses CNS disease in a mouse model of multiple sclerosis," PLoS One, vol. 9, no. 1, article e87712, 2014.

[89] S. Noroozi, H. A. E. Meimand, M. K. Arababadi, N. Nakhaee, and G. Asadikaram, "The effects of IFN- $\beta$ 1a on the expression of inflammasomes and apoptosis-associated speck-like proteins in multiple sclerosis patients," Molecular Neurobiology, vol. 54, no. 4, pp. 3031-3037, 2017.

[90] S. Malhotra, J. Río, E. Urcelay et al., "NLRP3 inflammasome is associated with the response to IFN- $\beta$ in patients with multiple sclerosis," Brain, vol. 138, no. 3, pp. 644-652, 2015.

[91] M. Inoue, P. H. Chen, S. Siecinski et al., "An interferon- $\beta$ resistant and NLRP3 inflammasome-independent subtype of EAE with neuronal damage," Nature Neuroscience, vol. 19, no. 12, pp. 1599-1609, 2016.

[92] C. Guo, J. W. Fulp, Y. Jiang et al., "Development and characterization of a hydroxyl-sulfonamide analogue, 5-chloro- $\mathrm{N}$-[2(4-hydroxysulfamoyl-phenyl)-ethyl]-2-methoxy-benzamide, as a novel NLRP3 inflammasome inhibitor for potential treatment of multiple sclerosis," ACS Chemical Neuroscience, vol. 8, no. 10, pp. 2194-2201, 2017.

[93] R. C. Coll, A. A. B. Robertson, J. J. Chae et al., "A smallmolecule inhibitor of the NLRP3 inflammasome for the treatment of inflammatory diseases," Nature Medicine, vol. 21, no. 3, pp. 248-255, 2015.

[94] A. Musella, G. Mandolesi, A. Gentile et al., "Cladribine interferes with IL- $1 \beta$ synaptic effects in experimental multiple sclerosis," Journal of Neuroimmunology, vol. 264, no. 1-2, pp. 8-13, 2013.

[95] H. Yu, M. Wu, G. Lu et al., "Prednisone alleviates demyelination through regulation of the NLRP3 inflammasome in a C57BL/6 mouse model of cuprizone-induced demyelination," Brain Research, vol. 1678, pp. 75-84, 2018.

[96] B. Z. Shao, W. Wei, P. Ke, Z. Q. Xu, J. X. Zhou, and C. Liu, "Activating cannabinoid receptor 2 alleviates pathogenesis of experimental autoimmune encephalomyelitis via activation of autophagy and inhibiting NLRP3 inflammasome," CNS Neuroscience \& Therapeutics, vol. 20, no. 12, pp. 10211028, 2014.

[97] T. Soundara Rajan, S. Giacoppo, F. Diomede, P. Bramanti, O. Trubiani, and E. Mazzon, "Human periodontal ligament stem cells secretome from multiple sclerosis patients suppresses NALP3 inflammasome activation in experimental autoimmune encephalomyelitis," International Journal of Immunopathology and Pharmacology, vol. 30, no. 3, pp. 238-252, 2017.

[98] J. R. Hodges, “Alzheimer’s centennial legacy: origins, landmarks and the current status of knowledge concerning cognitive aspects," Brain, vol. 129, no. 11, pp. 2811-2822, 2006.

[99] P. Scheltens, K. Blennow, M. M. B. Breteler et al., "Alzheimer's disease," The Lancet, vol. 388, no. 10043, pp. 505-517, 2016.

[100] A. Rubartelli, "DAMP-mediated activation of NLRP3inflammasome in brain sterile inflammation: the fine line between healing and neurodegeneration," Frontiers in Immunology, vol. 5, p. 99, 2014.

[101] A. Salminen, J. Ojala, A. Kauppinen, K. Kaarniranta, and T. Suuronen, "Inflammation in Alzheimer's disease: amyloid- $\beta$ oligomers trigger innate immunity defence via pattern recognition receptors," Progress in Neurobiology, vol. 87, no. 3, pp. 181-194, 2009.

[102] M. Saresella, F. la Rosa, F. Piancone et al., "The NLRP3 and NLRP1 inflammasomes are activated in Alzheimer's disease," Molecular Neurodegeneration, vol. 11, no. 1, p. 23, 2016.

[103] V. Kaushal, R. Dye, P. Pakavathkumar et al., "Neuronal NLRP1 inflammasome activation of caspase-1 coordinately regulates inflammatory interleukin-1-beta production and axonal degeneration-associated caspase- 6 activation," Cell Death \& Differentiation, vol. 22, no. 10, pp. 1676-1686, 2015.

[104] M. T. Heneka, M. P. Kummer, A. Stutz et al., "NLRP3 is activated in Alzheimer's disease and contributes to pathology in APP/PS1 mice," Nature, vol. 493, no. 7434, pp. 674-678, 2013.

[105] N. Murphy, B. Grehan, and M. A. Lynch, "Glial uptake of amyloid beta induces NLRP3 inflammasome formation via cathepsin-dependent degradation of NLRP10," NeuroMolecular Medicine, vol. 16, no. 1, pp. 205-215, 2014.

[106] J. M. Rubio-Perez and J. M. Morillas-Ruiz, "A review: inflammatory process in Alzheimer's disease, role of cytokines," The Scientific World Journal, vol. 2012, Article ID 756357, 15 pages, 2012.

[107] L. Liu and C. Chan, "The role of inflammasome in Alzheimer's disease," Ageing Research Reviews, vol. 15, pp. 6-15, 2014.

[108] M. Kitazawa, D. Cheng, M. R. Tsukamoto et al., "Blocking IL-1 signaling rescues cognition, attenuates tau pathology, and restores neuronal $\beta$-catenin pathway function in an Alzheimer's disease model," The Journal of Immunology, vol. 187, no. 12, pp. 6539-6549, 2011.

[109] J. M. Craft, D. M. Watterson, E. Hirsch, and L. J. van Eldik, "Interleukin 1 receptor antagonist knockout mice show enhanced microglial activation and neuronal damage induced by intracerebroventricular infusion of human $\beta$-amyloid," Journal of Neuroinflammation, vol. 2, no. 1, p. 15, 2005.

[110] C. Roodveldt, J. Christodoulou, and C. M. Dobson, "Immunological features of $\alpha$-synuclein in Parkinson's disease," Journal of Cellular and Molecular Medicine, vol. 12, no. 5B, pp. 1820-1829, 2008.

[111] M. G. Spillantini, R. A. Crowther, R. Jakes, M. Hasegawa, and M. Goedert, " $\alpha$-Synuclein in filamentous inclusions of Lewy bodies from Parkinson's disease and dementia with Lewy bodies," Proceedings of the National Academy of 
Sciences of the United States of America, vol. 95, no. 11, pp. 6469-6473, 1998.

[112] M. Mogi, A. Togari, T. Kondo et al., "Caspase activities and tumor necrosis factor receptor R1 (p55) level are elevated in the substantia nigra from parkinsonian brain," Journal of Neural Transmission, vol. 107, no. 3, pp. 335-341, 2000.

[113] T. Nagatsu, M. Mogi, H. Ichinose, and A. Togari, "Changes in cytokines and neurotrophins in Parkinson's disease," Journal of Neural Transmission Supplementum, vol. 60, pp. 277-290, 2000.

[114] P. Zhang, X. Y. Shao, G. J. Qi et al., "Cdk5-dependent activation of neuronal inflammasomes in Parkinson's disease," Movement Disorders, vol. 31, no. 3, pp. 366-376, 2016.

[115] H. Bai, B. Yang, W. Yu, Y. Xiao, D. Yu, and Q. Zhang, "Cathepsin B links oxidative stress to the activation of NLRP3 inflammasome," Experimental Cell Research, vol. 362, no. 1, pp. 180-187, 2018.

[116] V. Lawana, N. Singh, S. Sarkar et al., "Involvement of c-Abl kinase in microglial activation of NLRP3 inflammasome and impairment in autolysosomal system," Journal of Neuroimmune Pharmacology, vol. 12, no. 4, pp. 624-660, 2017.

[117] H. S. Chun, G. E. Gibson, L. A. DeGiorgio, H. Zhang, V. J. Kidd, and J. H. Son, "Dopaminergic cell death induced by $\mathrm{MPP}^{+}$, oxidant and specific neurotoxicants shares the common molecular mechanism," Journal of Neurochemistry, vol. 76, no. 4, pp. 1010-1021, 2001.

[118] P. Klevenyi, O. Andreassen, R. J. Ferrante, J. R. Schleicher Jr., R. M. Friedlander, and M. F. Beal, "Transgenic mice expressing a dominant negative mutant interleukin- $1 \beta$ converting enzyme show resistance to MPTP neurotoxicity," NeuroReport, vol. 10, no. 3, pp. 635-638, 1999.

[119] W. Wang, L. T. T. Nguyen, C. Burlak et al., "Caspase-1 causes truncation and aggregation of the Parkinson's diseaseassociated protein $\alpha$-synuclein," Proceedings of the National Academy of Sciences of the United States of America, vol. 113, no. 34, pp. 9587-9592, 2016.

[120] C. B. Hurelbrink, R. J. E. Armstrong, L. M. Luheshi, S. B. Dunnett, A. E. Rosser, and R. A. Barker, "Death of dopaminergic neurons in vitro and in nigral grafts: reevaluating the role of caspase activation," Experimental Neurology, vol. 171, no. 1, pp. 46-58, 2001.

[121] H. Mochizuki, H. Hayakawa, M. Migita et al., "An AAVderived Apaf-1 dominant negative inhibitor prevents MPTP toxicity as antiapoptotic gene therapy for Parkinson's disease," Proceedings of the National Academy of Sciences of the United States of America, vol. 98, no. 19, pp. 1091810923, 2001.

[122] G. Codolo, N. Plotegher, T. Pozzobon et al., "Triggering of inflammasome by aggregated $\alpha$-synuclein, an inflammatory response in synucleinopathies," PLoS One, vol. 8, no. 1, article e55375, 2013.

[123] A. Gustot, J. I. Gallea, R. Sarroukh, M. S. Celej, J. M. Ruysschaert, and V. Raussens, "Amyloid fibrils are the molecular trigger of inflammation in Parkinson's disease," Biochemical Journal, vol. 471, no. 3, pp. 323-333, 2015. 


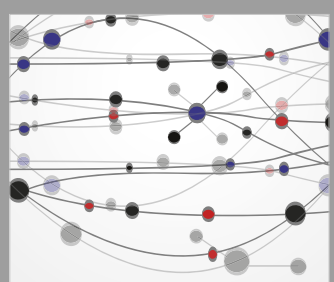

The Scientific World Journal
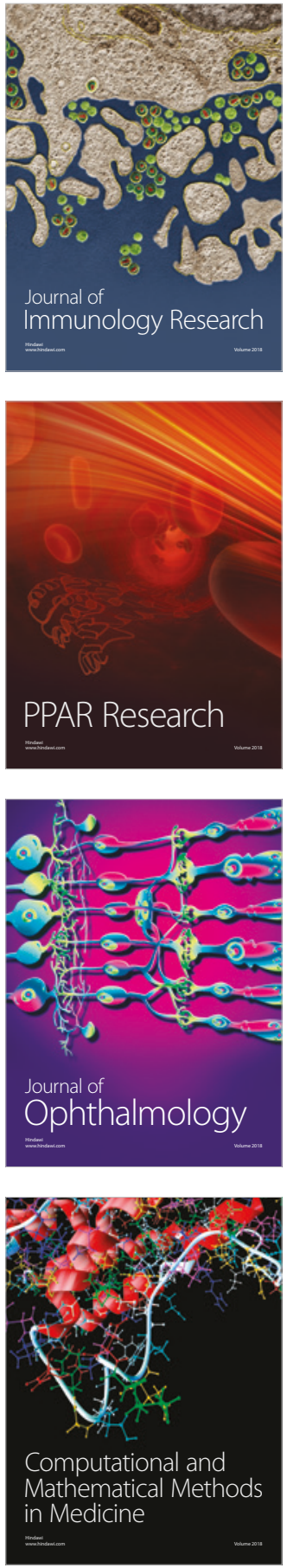

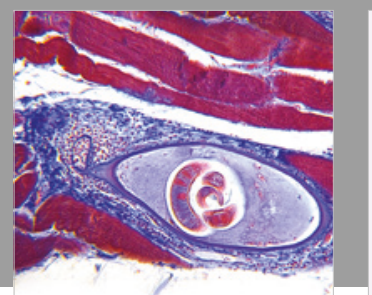

Gastroenterology Research and Practice

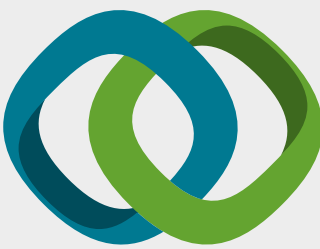

\section{Hindawi}

Submit your manuscripts at

www.hindawi.com
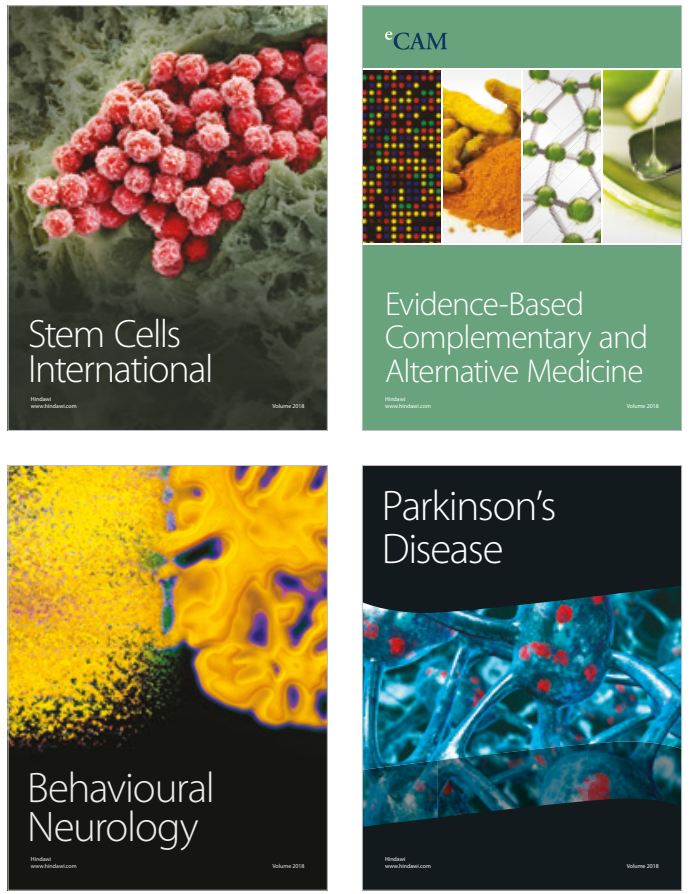

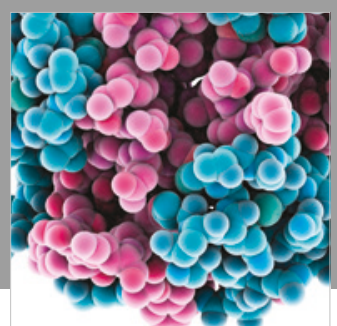

ournal of

Diabetes Research

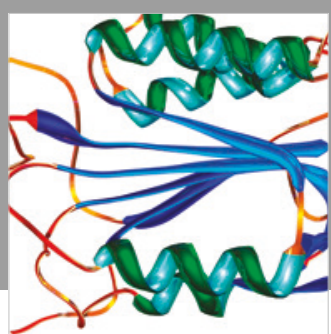

Disease Markers
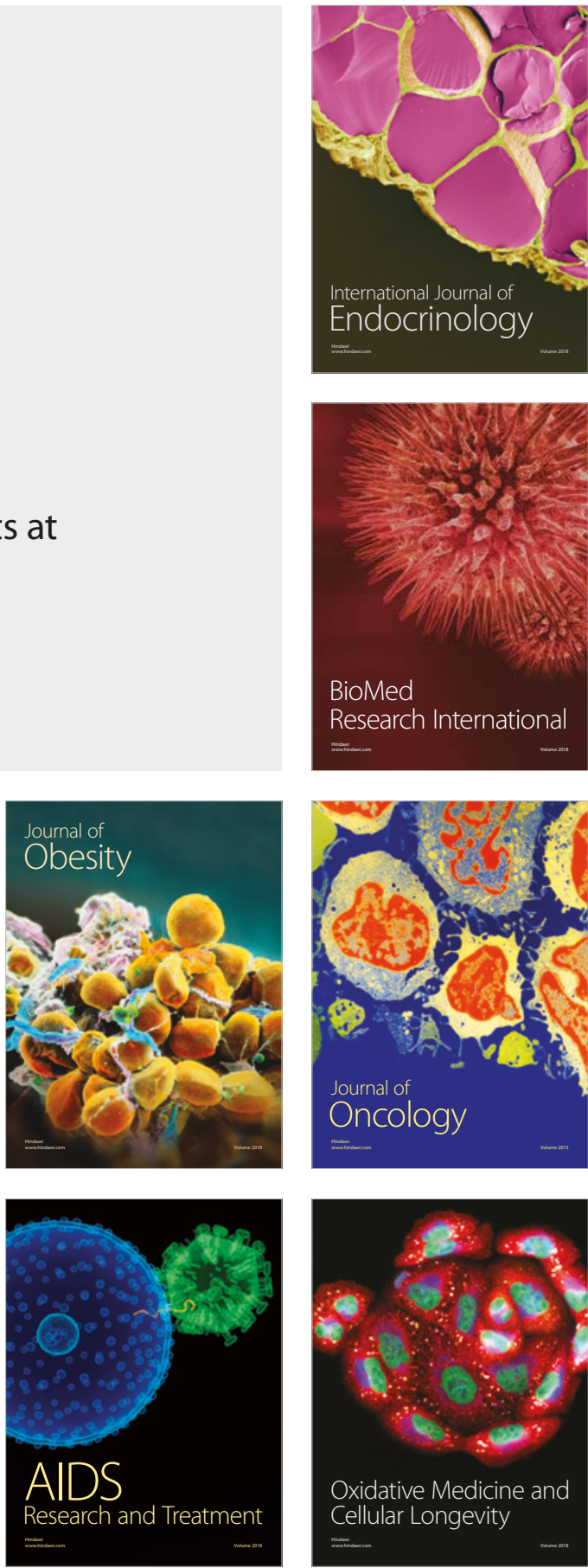